\title{
Normas e redistribuição: um estudo sobre condicionantes internacionais das políticas de combate ao racismo no Brasil
}

\author{
Norms and redistribution: a case study of international \\ influences over policies against racial discrimination in Brazil
}

RODRIGO DE OLIVEIRA GODINHO*

Rev. Bras. Polít. Int. 52 (1): 71-88 [2009]

\section{Introdução}

Este artigo apresenta dois objetivos centrais. Em primeiro lugar, busca desenvolver estudo de caso relativo aos canais de transmissão entre normas internacionais e políticas redistributivas. Neste contexto, examina como o reconhecimento e a exposição do Estado a normas e instituições internacionais podem condicionar a implementação de políticas redistributivas no âmbito doméstico. De acordo com a principal hipótese do estudo, a "abertura" do Estado ao ambiente internacional pode alterar o equilíbrio doméstico entre coalizóes contrárias e favoráveis a políticas redistributivas, contribuindo - por meio de distintos "mecanismos de transmissão" - para a superação de obstáculos políticos à redistribuição.

Em segundo lugar, no artigo pretende-se discutir condicionantes e incentivos internacionais à trajetória recente das políticas de combate à discriminação racial no Brasil, no âmbito da discussão mais geral sobre a relação entre normas internacionais e possibilidades de redistribuição. Tem sido amplamente documentada a presença de desigualdades raciais significativas no Brasil, cuja moderação requereria a implementação de políticas baseadas em dois modelos fundamentais: enfoques repressivos e valorizativos ${ }^{1}$; ou políticas de ação afirmativa, que apresentariam natureza compensatória e redistributiva. $\mathrm{O}$ estudo de caso tem como objeto particular as políticas implementadas no período 1995-2005,

\footnotetext{
* Doutor em Relaçôes Internacionais pela Universidade de Brasília - UnB e diplomata de carreira (rodgodinho@yahoo.com.br).

1 JACCOUD, Luciana; BEGHIN, Nathalie. Desigualdades Raciais no Brasil: um balanço da intervenção governamental. Brasília: Ipea, 2002. p.55-56.
} 
o qual se caracterizaria por relativa continuidade no sistema político doméstico, em particular no que toca às preferências do Poder Executivo relativas ao objeto de estudo.

Para fins de apresentação, o artigo está dividido em cinco seções: a) normas internacionais e políticas redistributivas: teoria; b) as normas internacionais de combate à discriminação racial; c) breve histórico da política brasileira de combate à discriminação racial; d) a política brasileira de combate à discriminação racial entre 1995 e 2005; e) conclusões.

\section{Normas internacionais e políticas redistributivas: teoria}

As políticas redistributivas têm sido objeto de atenção considerável no âmbito das literaturas teórica e empírica da economia política. A "economia política" da redistribuição enfatiza o peso de determinantes de natureza política - e mais especificamente, de natureza eleitoral - sobre a dimensão e o alcance de programas governamentais de características redistributivas. ${ }^{2}$ Embora demonstre como a implementação de políticas redistributivas pode defrontar-se com obstáculos expressivos, dependendo de composição política entre os interesses de grupos sociais beneficiados e prejudicados, tal literatura se limita à consideração dos condicionantes domésticos de políticas redistributivas.

O impacto de normas internacionais sobre as possibilidades domésticas de implementação de políticas redistributivas é tema cujo exame se ampara na conjugação de dois padrões de construções teóricas: modelos de interação entre os ambientes doméstico e internacional; e modelos que detalham os efeitos de normas e de instituições internacionais sobre processos tanto sistêmicos como domésticos.

Característica marcante da produção teórica em relações internacionais, em particular nas últimas duas décadas, tem sido a construção de modelos que buscam integrar as dinâmicas políticas nos âmbitos doméstico e internacional. Os modelos de "variância residual" buscam integrar a política doméstica a teorias fundamentalmente sistêmicas; nestes modelos de equilíbrio parcial, a política doméstica tende a ser representada como variável interveniente que introduz "variância residual" em torno das previsões usualmente decorrentes de pressões sistêmicas. Em contraste, os "jogos de dois níveis" baseiam-se em modelos de equilíbrio geral que examinam a interação estratégica entre fatores domésticos e internacionais. ${ }^{3}$

Por outro lado, a busca de maior compreensão sobre o significado e o impacto de normas e instituições internacionais resultou na elaboração de três distintos

2 ROBERTS, Kevin. Voting Over Income Tax Schedules. Journal of Public Economics. Vol. 8, p. 329-340, 1977.

3 MORAVCSIK, Andrew. Introduction - integrating international and domestic theories of international bargaining. In: EVANS, Peter B.; JACOBSON, Harold K.; PUTNAM, Robert D. Double-Edged Diplomacy - international bargaining and domestic politics. Berkeley: University of California Press, 1993. 490p. pp. 3-42. 
conjuntos de modelos teóricos: a) modelos que estudam os impactos de instituições sobre a estrutura de incentivos com que se defrontam os Estados; b) modelos que estudam os impactos sobre a estrutura de representação com que se defrontam os atores domésticos; e c) modelos que examinam os impactos das instituições sobre a própria estrutura de identidade de Estados e de atores domésticos.

O primeiro grupo de modelos - vinculados à teoria dos "regimes internacionais" - ressalta os impactos de normas e de instituiçôes sobre os incentivos que condicionam a atuação de atores internacionais, em contextos de interdependência estratégica, particularmente no tocante à definição das possibilidades de cooperação no sistema interestatal. ${ }^{4}$

$\mathrm{O}$ segundo grupo de modelos ressalta que normas internacionais teriam impacto primário sobre a "estrutura de representação" de grupos domésticos, afetando a forma como são condicionadas e agregadas as preferências de atores domésticos e são definidas as preferências coletivas. Neste contexto, normas internacionais facilitariam a remoção de obstáculos a determinados resultados e criariam incentivos a que grupos governamentais e privados domésticos busquem "pontos de apoio" internacionais a seus interesses específicos. Na busca de tais "pontos de apoio", os grupos domésticos buscariam, sobretudo, reforçar sua posição relativa no jogo político doméstico, o que se aplicaria tanto a atores estatais - que, na posição de "iniciadores" de políticas públicas, teriam interesse em minimizar "pontos de veto" domésticos - como a grupos privados potencialmente beneficiados pela internacionalização de determinados processos políticos. ${ }^{5}$

O terceiro grupo de modelos ressalta que normas e instituições internacionais teriam impactos fundamentais sobre a "estrutura de identidade" de Estados e de grupos domésticos, afetando a forma como são constituídas as preferências de atores sociais. Teorias de inspiração sociológica - a Escola Inglesa e a abordagem construtivista das relações internacionais - constituiriam o núcleo central de contribuições a ressaltar o efeito "constitutivo" das instituições internacionais.

A consideração dos três grupos de modelos permitiria a identificação de três mecanismos principais de influência das instituições internacionais sobre atores sociais, estatais e não-estatais: a) contratação - interação que permite melhoras a todas as partes negociantes, sem a piora de qualquer parte (melhoria no sentido de Pareto), por meio da manipulação de incentivos; b) coerção - interação que torna possível piora de bem-estar para algumas das partes negociantes, sobretudo em cenários de conflito distributivo, por meio da manipulação de sanções e do exercício de restrições externas; c) persuasão - interação que permite mudanças no ordenamento de preferências dos atores, a partir de novos modelos de compreensão intersubjetiva.

4 KEOHANE, Robert. After Hegemony - cooperation and discord in the World Political Economy. Princeton: Princeton University Press, 1984. 290p.

5 DREZNER, Daniel W. (ed.). Locating the Proper Authorities - the interaction of domestic and international institutions. Michigan: the University of Michigan Press, 2003. 280p. 
A apreciação teórica da relação entre instituiçõos internacionais e política redistributiva - que implica presença e identificação de grupos "perdedores" e "ganhadores" no jogo político doméstico - pode beneficiar-se com particular intensidade dos insights provenientes dos modelos relativos às estruturas de representação e de identidade. Para tanto, deve reconhecer que, ao se ampararem em normas internacionais, atores domésticos freqüentemente buscam reforçar sua posição no jogo doméstico; ao mesmo tempo, deve superar a dicotomia entre os motivos específicos das duas categorias de atores - estatais e privados -, por meio de síntese analítica que reconheça a possibilidade de formação de coalizôes domésticas entre atores estatais e grupos privados.

De acordo com esta perspectiva, baixas intensidade e freqüência de políticas redistributivas não necessariamente refletiriam preferências do "Estado", podendo antes constituir o resultado de equilíbrio político, no plano doméstico, que bloqueia sua implementação. Neste cenário, a presença de normas e de instituições internacionais pode ser fator decisivo para assegurar a prevalência da coalizão "redistributivista", com vistas a superar tanto "pontos de veto" à implementação de políticas públicas.

O impacto de normas/instituições internacionais sobre o jogo doméstico seria observado a partir dos canais de contratação, persuasão e coerção, mencionados anteriormente, e a partir de um quarto canal, denominado de mobilização. Tal canal contemplaria a possibilidade de que "pontos de apoio" internacionais podem revelar-se decisivos para a configuração relativa de coalizões domésticas favoráveis e contrárias a determinadas políticas públicas. Ainda que tenha ocorrência limitada no tempo - caso, por exemplo, associada à realização de conferências -, a afirmação de normas/instituiçôes internacionais pode gerar momentum político que viabiliza a prevalência (ainda que temporária) de determinada coalizão no jogo político doméstico. Neste contexto, possibilitaria a implementação de políticas que, na ausência de tal "impulso mobilizador", não seriam politicamente viáveis.

Naturalmente, o alcance e os impactos de tais canais e mecanismos de transmissão dependeriam de diversos parâmetros: sensibilidade das preferências estatais à pressão internacional; graus de organização das coalizôes domésticas e de acesso ao processo decisório; e custos "sistêmicos", de "audiência" e de "reputação" associados ao descumprimento de normas internacionais. Tais elementos conformariam distintas possibilidades de equilíbrio, entre as quais se destacariam: a) "integração plena", situação em que a abertura ao ambiente internacional se traduz em incentivos consistentes para a implementação de políticas redistributivas no âmbito doméstico - tal resultado estaria associado à existência de significativa pressão sistêmica pela adesão a normas internacionais, bem como de elevados graus de organização da coalizão doméstica pró-redistribuição e de permeabilidade do processo decisório a pressões internacionais; b) "integração incipiente", situação em que a abertura ao ambiente internacional não gera incentivos suficientemente fortes para a implementação de políticas redistributivas internas - tal resultado 
seria associado à existência de elevados custos para o exercício da ação coletiva internacional, bem como de graus limitados de organização da coalizão doméstica pró-redistribuição e de permeabilidade do processo decisório a pressóes internacionais. ${ }^{6}$

\section{Normas internacionais e combate à discriminação racial}

A implementação de políticas domésticas de combate à discriminação racial tem um de seus pontos de apoio na existência de normas e instituições internacionais que buscam prevenir e eliminar a ocorrência do racismo.

Pode-se argumentar que tal ambiente normativo já se traduzia em pressão internacional entre os anos 60 e 80, ainda que de forma menos intensa do que aquela observada no período posterior. Dois fatores foram fundamentais para a conformação de tal quadro, sendo o primeiro o processo de descolonização, que possibilitou a emergência de número significativo de atores internacionais, sensíveis ao racismo em virtude de sua experiência histórica, e cuja atuação foi favorecida pelas possibilidades de barganha estratégica abertas pelo conflito Leste-Oeste. $\mathrm{O}$ segundo fator foi a visibilidade alcançada pela questão em decorrência do regime de apartheid na África do Sul, que atraiu o repúdio sistemático da comunidade internacional, a ponto de possibilitar a aprovação, no âmbito do Conselho de Segurança das Nações Unidas, de um regime de sanções contra o país nos anos 70 .

Embora se observem indícios de pressão sistêmica, os meios de pressão internacional ainda apresentavam limitações significativas. Observa-se evolução gradual dos instrumentos à disposição da comunidade internacional a partir de 1970, quando é estabelecido o "Procedimento 1503" da CDH - mecanismo de exame confidencial de denúncias de violações de direitos humanos. A partir dos anos 80 , observa-se proliferação de instrumentos extra-convencionais de proteção dos direitos humanos, com a criação de uma série de relatores por país - com mandatos de monitoramento da situação dos direitos humanos em países específicos -, e de relatores temáticos - com mandatos de monitoramento de direitos específicos em todo o mundo. $\mathrm{O}$ tratamento das denúncias de violações passa por transformações no âmbito da $\mathrm{CDH}$ - com o recurso crescente a procedimentos públicos -, e são criadas instâncias de diálogo com organizações não-governamentais nos principais organismos internacionais. Em síntese, no período ocorreu a construção gradual de uma estrutura de pressão da comunidade internacional em prol da proteção dos direitos humanos.

Em termos específicos, o imediato pós-segunda Guerra Mundial ensejou o empenho da comunidade internacional na criação de instrumentos e na convocação de conferências destinados a combater o racismo. Os delitos de natureza

6 GODINHO, Rodrigo. Normas internacionais e distribuição: caminhos da politica redistributiva em jogos de dois niveis. Tese de Doutorado. Universidade de Brasília/Irel, 2007. 
racista cometidos pelo regime nazista teriam constituído inspiração inicial para a construção de estruturas institucionais e normativas, no âmbito das Nações Unidas, destinadas a combater o fenômeno, processo que ganhou impulso com o movimento de descolonização. ${ }^{7}$

Teve importância central a adoção pela Assembléia Geral das Nações Unidas (AGNU), em dezembro de 1965, da Convenção Internacional sobre a Eliminação da Discriminação Racial, em vigor a partir de 1969. Vários de seus artigos reproduziram elementos já presentes na Declaração Universal das Nações Unidas sobre a Eliminação de Todas as Formas de Discriminação Racial, de novembro de 1963. Tanto a Declaração como a Convenção procuram definir o fenômeno da discriminação racial e estabelecer compromissos dos Estados - nos planos político, legislativo e administrativo - de combate ao problema. Para os propósitos do artigo, apresentam particular interesse os dispositivos - nos artigos $1^{\circ}$ e $2^{\circ}$ - que estimulam a adoção de ação afirmativa em defesa de grupos em situação de inferioridade no âmbito das sociedades nacionais. ${ }^{8}$

A Convenção cria mecanismo de supervisão das obrigações - o Comitê para a Eliminação da Discriminação Racial (Cerd) - com funçôes de: a) assessoramento e supervisão, por meio do exame periódico das medidas implementadas pelos Estados com vistas ao cumprimento de suas obrigações; b) conciliação, para casos objeto de queixas interestatais; e c) investigação, relativa a queixas ou comunicaçóes individuais, nos casos de Estados que tenham opcionalmente reconhecido a competência do Cerd para receber e examinar tais queixas.

O período compreendido pelas décadas de 1970 e 1980 também foi marcado por intenso exercício de convocação de conferências e de estabelecimento de compromissos, os quais definiram as bases do soft law a regular a atuação dos Estados na matéria. Em 1972, a AGNU proclamou a Década de Ação para o Combate ao Racismo e à Discriminação Racial, procurando mobilizar a comunidade internacional por meio de ações nos planos nacional, regional e internacional. ${ }^{9}$ A constatação de que os objetivos da Primeira Década não haviam sido plenamente alcançados levou a Assembléia Geral a proclamar a Segunda Década de Ação para o Combate ao Racismo e à Discriminação Racial, prevendo uma série de iniciativas - entre 1983 e 1992 - nos campos educacional, de proteção de minorias e de combate ao apartheid. ${ }^{10}$

7 ALVES, José Augusto Lindgren. A Arquitetura Internacional dos Direitos Humanos. São Paulo: FTD, 1997. p. 87.

8 UNITED NATIONS. International Convention on the Elimination of All Forms of Racial Discrimination. New York, 1965.

9 UNITED NATIONS. First Decade to Combat Racism and Racial Discrimination. General Assembly resolution 3057 (XXVIII). New York, 1973.

10 UNITED NATIONS. Second Decade to Combat Racism and Racial Discrimination. General Assembly resolution 387 (XIV). New York, 1983. 
Em 1978, realizou-se em Genebra a Primeira Conferência Mundial para o Combate ao Racismo e à Discriminação Racial, ocasião em que se aprovou Plano de Ação prevendo iniciativas nos planos nacional e internacional. A Segunda Conferência Mundial para o Combate ao Racismo e à Discriminação Racial também se realizou em Genebra, no ano de 1983, e procurou avaliar as atividades realizadas no período 1973-1983, formulando medidas específicas nos campos do combate ao apartheid, da educação e treinamento, dos meios de comunicação, da promoção dos direitos de minorias e da implementação de instrumentos internacionais.

A análise das declaraçõos políticas e dos planos de ação aprovados permite delinearem-se alguns elementos adicionais que caracterizam o tratamento do tema durante o período. Em comparação com instrumentos aprovados em período mais recente, percebe-se que aqueles documentos confeream peso especial a açôes - de natureza assistencial ou estrutural - a serem implementadas no plano internacional. O programa de ação da Primeira Conferência apresenta, por exemplo, 19 parágrafos dedicados às medidas a serem adotadas no plano internacional, em comparação com 14 parágrafos que descrevem as medidas relativas ao plano nacional.

A ação internacional proposta compreendia vertente "assistencial", composta tanto por mandatos específicos para órgãos e agências especializadas das Nações Unidas, como por medidas de natureza financeira - de que é exemplo a idéia, apresentada no Programa da Primeira Década, de que a "Assembléia Geral deveria estabelecer um fundo internacional em bases voluntárias para auxiliar os povos em luta contra a discriminação racial e o apartheid". A vertente "estrutural" apresentava características distintas, já que, em nome do combate ao racismo, ecoava propostas de ações redistributivas no plano mundial, como o estabelecimento de uma nova ordem econômica internacional, caracterizada nas duas conferências como um "importante meio de combate às causas que geram o racismo e a discriminação racial".

Observam-se características distintas no período que tem início nos anos 90. A Terceira Década de Ação para o Combate ao Racismo e à Discriminação Racial foi proclamada em 1993, mesmo ano em que se realizou a Conferência de Viena sobre os Direitos Humanos e foi designado Relator Especial da CDH sobre Formas Contemporâneas de Racismo e Discriminação Racial. A Terceira Década apresentou visão mais ampla do fenômeno do racismo, à luz dos acontecimentos que estavam gerando transformações significativas na realidade internacional ${ }^{11}$.

Tal tendência manifestou-se com particular intensidade na Terceira Conferência Mundial contra o Racismo, realizada em Durban, África do Sul, em 2001. A Declaração e o Plano de Ação aprovados na Conferência de Durban apresentam enfoques distintos e introduzem novos temas nas considerações

11 UNITED NATIONS. Third Decade to Combat Racism and Racial Discrimination. General Assembly resolution 48 (LXXXI). New York, 1993. 
relativas ao racismo. Em particular, altera-se o peso relativo das iniciativas de combate ao racismo a serem implementadas nos planos nacional e internacional, conforme o diagnóstico de que

“... os obstáculos para superar a discriminação racial e alcançar a igualdade racial residem, principalmente, na ausência de vontade política, na inexistência de legislação eficiente, na falta de estratégias de implementação e de medidas concretas por parte dos Estados" (parágrafo 79).

Confere-se destaque à necessidade de implementação em nível nacional de políticas e legislação adequadas, com atenção particular a medidas positivas em favor das vítimas de racismo. Tais políticas especiais ou positivas são detalhadas, incorporando objetivos como

“... o alcance de representação adequada nas instituições educacionais, de moradia, nos partidos políticos, nos parlamentos, no emprego, especialmente nos serviços judiciários, na polícia, exército e outros serviços civis".

A alteração de peso relativo é sentida, por exemplo, no capítulo do plano de ação relativo às medidas de prevenção, educação e proteção, que apresenta 82 parágrafos sobre medidas a serem adotadas no âmbito nacional e 9 parágrafos sobre medidas no âmbito internacional.

O tratamento internacional do combate ao racismo a partir dos anos 90 aponta, portanto, tendências de ampliação das normas relativas ao ordenamento doméstico e às políticas no âmbito interno, em detrimento de normas relativas a transformações estruturais no sistema internacional. À luz da evolução do quadro normativo internacional, as próximas seções analisam a implementação de políticas contra o racismo no Brasil.

\section{Breve histórico da política brasileira de combate à discriminação racial}

O exame da relação entre ambiente internacional e a formulação de políticas públicas de combate à discriminação racial no Brasil permite a identificação de dois períodos distintos. O primeiro compreenderia as décadas de 1960, 1970 e 1980, podendo-se adotar como marcos os anos de 68 - quando o Brasil ratifica a Convenção para a Eliminação da Discriminação Racial -, e 88 - quando é adotada uma nova Constituição. Pode-se argumentar que a relação entre os cenários internacional e doméstico criou condições para que o país se encontrasse, no tocante à questão racial, em situação de "integração incipiente" ao ambiente normativo internacional.

Conforme ressaltado na seção anterior, os meios de pressão internacional ainda apresentavam limitações significativas, ainda que gerassem incentivos sistêmicos 
para a adesão ao ambiente normativo. Por outro lado, a realidade doméstica no Brasil seria caracterizada por barreiras no estabelecimento de canais regulares de diálogo entre governo e sociedade - com dificuldades de auto-organização, por parte dos grupos domésticos, e de acesso institucional ao processo decisório - e por baixo custo interno de descumprimento das normas internacionais.

O Brasil efetivamente assumiu obrigaçōes e compromissos internacionais no período: a) apoiou a proclamação, em 1963, da Declaração das Nações Unidas sobre a Eliminação da Discriminação Racial; b) assinou, em 1965, a Convenção sobre a Eliminação da Discriminação Racial, ratificada em 1968; c) assinou a Convenção 111 da Organização Internacional do Trabalho (OIT), concernente à Discriminação em Matéria de Emprego e Profissão (1968), assim como a Convenção Relativa à Luta contra a Discriminação no Campo do Ensino (1968); e d) participou, em 1978 e 1983, das I e II Conferências Mundiais de Combate ao Racismo.

No entanto, tal foi uma adesão matizada, na medida em que partiu das premissas de que haveria democracia racial no país, de que a mestiçagem seria vocação peculiar brasileira, de que a escravidão teria trazido benefícios ao país, e de que no Brasil não haveria conflitos raciais. À época, o Movimento Negro já procurava denunciar o "mito" da democracia racial. Embora sua organização e eficácia de atuação somente se tenham consolidado durante os anos 80, com a construção de espaços de atuação no âmbito do Estado ${ }^{12}$, o movimento já estava em processo de reorganização na década de $1970 .{ }^{13}$

A combinação entre tais desdobramentos refletiu-se nas características das poucas iniciativas de combate à discriminação racial adotadas no período, que privilegiaram enfoques repressivos e valorizativos, em detrimento de políticas de ação afirmativa.

A partir da redemocratização, foram esboçadas as primeiras iniciativas especificamente voltadas para a promoção da igualdade racial. O governo estadual de São Paulo criou, em 84, o Conselho de Participação e Desenvolvimento da Comunidade Negra, com o objetivo de formular políticas de valorização da população negra, experiência seguida da criação de diversos conselhos estaduais e municipais. Ainda nos anos 80, o Patrimônio Histórico tombou símbolos da cultura negra, como a Serra da Barriga, sede do Quilombo dos Palmares, em Alagoas, no ano de 86 . Também se registram a proclamação do dia 20 de novembro, aniversário da morte de Zumbi dos Palmares, como o Dia Nacional da Consciência Negra, e a fundação do Memorial Zumbi.

$\mathrm{O}$ ano de 88 representa marco no tratamento da questão racial, uma vez que a Constituição Federal estabeleceu parâmetros para o combate à discriminação

12 JACCOUD, Luciana; BEGHIN, Nathalie. Op.cit. p.15.

13 RIBEIRO, Matilde. Diversidade Racial, Étnica e Processos de Participação Politica na América Latina. Instituto Interamericano de Derechos Humanos, 2001. 
racial no Brasil. Contribuição fundamental da Constituição foi a criminalização do racismo, reforçada por leis infraconstitucionais posteriores - como a Lei no. 7716 (89), que definiu os crimes resultantes de preconceito de raça ou cor, e a Lei no. 9459 (97), que estabeleceu a punição dos crimes resultantes de discriminação ou preconceito de raça, cor, etnia, religião ou procedência nacional.

Em fins da década de 1980, observa-se transição rumo ao segundo período, marcado pelo progressivo estabelecimento de novo padrão de relação entre ambiente internacional e políticas domésticas de combate ao racismo. Como exemplo, pode-se assinalar a criação da Fundação Cultural Palmares, em 1988, fato expressivo ao representar, no âmbito do Executivo Federal, instituição com mandato especificamente direcionado para os interesses da população negra, inicialmente circunscrito ao plano cultural. A transição rumo à conformação de novos princípios e políticas de combate ao racismo no Brasil intensificou-se nos anos 90 e tornou-se plenamente visível no período 1995-2005.

\section{A política brasileira de combate à discriminação racial entre 1995 e 2005}

O período que tem início em 95 caracteriza-se pela mudança de titularidade no Poder Executivo, bem como pela intensificação de iniciativas e políticas com o objetivo de combater a discriminação racial, o que obedece a duas ordens de fatores.

O primeiro fator consiste na mudança das posições oficiais do Governo brasileiro sobre a discriminação racial. Já no discurso de posse do Presidente Fernando Henrique Cardoso, o governo brasileiro reconheceu oficialmente, pela primeira vez, a existência de preconceito e de discriminação racial no país, e salientou a necessidade de interlocução política com o Movimento Negro. ${ }^{14}$ As preferências governamentais no período podem ser apreendidas a partir de documentos como discursos e entrevistas. Tais fontes revelam o interesse governamental em promover a igualdade de oportunidades no país - inclusive por meio do exame das experiências adotadas nos Estados Unidos -, com o intuito de gerar "oportunidades quase compulsórias para compensar os desequilíbrios sociais e as discriminações existentes"; ainda não se observam, contudo, propostas explícitas de ação afirmativa no início do período. ${ }^{15}$ Também se depreende dos documentos a noção de que a implementação de políticas de ação afirmativa encontraria forte resistência no âmbito da sociedade brasileira - em entrevista, o Presidente Fernando Henrique Cardoso afirmou não ser contrário a políticas de ação afirmativa, salientando que as mesmas se defrontariam com resistência significativa na sociedade brasileira. ${ }^{16}$

14 CARDOSO, Fernando Henrique. Discurso de Posse no Congresso Nacional. Brasília, 1995.

15 BRASIL. Ministério da Justiça/SEDH. Construindo a democracia racial. Brasília, 2000.

16 TOLEDO, Roberto Pompeu. O Presidente segundo o sociólogo. São Paulo: Companhia das Letras, 1995. 
O segundo fator ressaltado seria o grau de organização já alcançado à época pelo Movimento Negro. Tal fator se tornou evidente com a realização da "Marcha Zumbi dos Palmares contra o racismo, pela cidadania e a vida", em novembro de 95 , com a participação de dezenas de milhares de pessoas, e resultando em documento com diagnóstico sobre o racismo e programa de ações. No conjunto de reivindicações então apresentadas, já se destacavam propostas de ação afirmativa, como o estabelecimento de incentivos fiscais às empresas que adotassem programas de promoção da igualdade racial, o desenvolvimento de ações afirmativas para acesso à universidade e a cursos profissionalizantes, e a promoção da representação proporcional dos grupos étnicos/raciais nas campanhas de comunicação do governo.

Também se deve destacar a criação, por decreto presidencial, do Grupo de Trabalho Interministerial de Valorização da População Negra (GTI População Negra) - vinculado ao Ministério da Justiça -, na mesma data da Marcha Zumbi dos Palmares. Proposto no âmbito do governo, a partir da mobilização de setores do Movimento Negro, entre os objetivos do Grupo se incluíram propor açōes de combate à discriminação racial e estimular ações da iniciativa privada. $\mathrm{O}$ formato do GTI - colegiado de representantes da sociedade civil e do governo - representou novidade, uma vez que possibilitou a emergência de canal institucional de diálogo direto do Movimento Negro com o governo. Em 1998, o GTI População Negra apresentou seus principais resultados à presidência da República, propondo iniciativas inclusive na área de políticas afirmativas, com atenção particular aos campos de educação, mercado de trabalho e comunicação social.

Paralelamente à instalação do GTI População Negra, o Ministério da Justiça lançou o I Programa Nacional dos Direitos Humanos (I PNDH), em 96, o qual apresentou tópico especificamente destinado à população negra. Ao estipular metas para as ações de combate ao racismo, o I PNDH faz alusão explícita ao desenvolvimento de ações afirmativas, entre as quais: a) estimular a presença de grupos étnicos diferenciados em propagandas institucionais contratadas pelo governo; b) apoiar as açōes da iniciativa privada que realizem discriminação positiva; e c) desenvolver açôes afirmativas para acesso à universidade e a cursos profissionalizantes. ${ }^{17}$

Ao mesmo tempo em que a abertura do Estado à sociedade civil se traduziu em pressão "de baixo", a adesão do Estado brasileiro ao regime internacional de promoção e proteção dos direitos humanos favoreceu cenário de pressão "de cima”, com vistas à atuação mais incisiva do governo no combate ao racismo. Neste contexto, observou-se a adesão do país aos principais tratados internacionais de direitos humanos, além da Convenção para a Eliminação da Discriminação Racial: Convenção para a Eliminação da Discriminação contra a Mulher, em 84; Convenção contra a Tortura, em 89; Convenção sobre os Direitos da Criança, em 90; e Pactos Internacionais de Direitos Civis e Políticos e de Direitos Econômicos,

17 BRASIL. Ministério da Justiça. Programa Nacional de Direitos Humanos. Brasília, 1996. 
Sociais e Culturais, em 92. Tal movimento fortaleceu-se com o reconhecimento da competência contenciosa da Corte Interamericana de Direitos Humanos, em 98, e a definição de um novo padrão de diálogo e de relacionamento com os mecanismos extra-convencionais de monitoramento dos direitos humanos. O Brasil intensificou o diálogo com tais mecanismos, recebendo visitas de relatores especiais - como os Relatores Especiais sobre a Tortura, sobre o Direito à Alimentação, e sobre Execuçōes Sumárias ou Arbitrárias -, e estendendo-lhes, no ano de 2001, convite permanente (standing invitation) para visitas ao Brasil.

Em 92, organizações sindicais de trabalhadores denunciaram, à Organização Internacional do Trabalho (OIT), a existência de discriminação racial no mercado de trabalho brasileiro, denúncia a que o Ministério do Trabalho e Emprego procurou reagir por meio de medidas. A partir de 95, o ministério iniciou parceria com a OIT - por meio do Programa para a Implementação da Convenção 111 para a adoção de políticas de combate à discriminação no mercado de trabalho. Em 96, decreto presidencial criou, no âmbito do MTE, o Grupo de Trabalho para a Eliminação da Discriminação no Emprego e na Ocupação (GTDEO), de composição também múltipla (representantes governamentais, de trabalhadores, de empregadores e do Ministério Público do Trabalho), e com a missão de elaborar plano de ações. Um de seus desdobramentos foi o lançamento, em 97, do Programa Brasil, Gênero e Raça, que resultou na implementação, nas Delegacias Regionais do Trabalho, de Núcleos de Promoção da Igualdade de Oportunidades e de Combate à Discriminação no Emprego e na Profissão.

Em 93, o Brasil apoiou a proclamação da "Terceira década para a eliminação do racismo e da discriminação Racial”, no âmbito da AGNU. Na mesma ocasião, apoiou a criação de relatoria especial sobre as formas contemporâneas de racismo, discriminação racial, xenofobia e intolerância, no âmbito da $\mathrm{CDH}$. O relator Maurice Glélé-Ahanhanzo visitou o Brasil em 95, a convite do governo brasileiro, e apresentou relatório e críticas sobre a situação racial no Brasil à $\mathrm{CDH}$, em 96.

A abertura ao ambiente internacional também se manifestou no plano do relacionamento do Brasil com o Comitê para a Eliminação da Discriminação Racial. Em 1996, o governo brasileiro encaminhou relatório consolidado ao Comitêt $^{18}$. Em sua apreciação do documento, o Cerd considerou como insuficientes as medidas até então adotadas pelo Governo brasileiro, sublinhou a necessidade de que o Brasil desenvolvesse indicadores para avaliar as políticas de proteção dos direitos de pessoas vulneráveis, e recomendou ao governo brasileiro fazer a declaração facultativa de reconhecimento da competência do Cerd para tramitar denúncias de violações no Brasil dos direitos cobertos na Convenção. ${ }^{19} \mathrm{~A}$ assinatura da declaração facultativa ocorreu em 2002.

18 BRASIL. Ministério das Relaçôes Exteriores e Ministério da Justiça. Décimo Relatório Periódico Relativo à Convenção Internacional Sobre a Eliminação de Todas as Formas de Discriminação Racial. Brasília: 1996. 122p.

19 Committee on the Elimination of Racial Discrimination. Concluding Observations of the Committee on the Elimination of Racial Discrimination: Brazil. (CERD/C/304/Add.11). Geneva, 1996. 
A partir de 2000 - quando tem início a preparação da participação do Brasil na Conferência de Durban -, podem-se observar indícios de que o Brasil estaria em situação de "integração plena" ao ambiente normativo internacional. $\mathrm{Na}$ seqüência da mobilização relacionada à conferência, passam a ser implementadas diversas medidas de ação afirmativa. Não se observara, anteriormente, equilíbrio político favorável à sua implementação, a despeito de tais medidas estarem previstas na Convenção para a Eliminação da Discriminação Racial e nos instrumentos internacionais subseqüentes, e de contarem com o apoio do Movimento Negro e de setores do Executivo brasileiro.

O processo de preparação para Durban resultou em significativa mobilização da coalizão doméstica favorável à ação afirmativa, em decorrência tanto da publicidade conferida ao tema como, principalmente, da criação de outros canais de acesso ao processo decisório. Em setembro de 2000, foi criado o Comitê Nacional para a preparação da participação brasileira em Durban - composto por representantes do governo federal, da sociedade civil, da Câmara dos Deputados e do Ministério Público Federal -, com o mandato de definir as posiçóes brasileiras a serem defendidas durante a Conferência. Com o intuito de subsidiar as atividades do Comitê, foram realizados encontros e conferências em todo o país.

Tal processo culminou na realização, em julho de 2001, da Conferência Nacional contra o Racismo e a Intolerância, com a presença de 1.700 delegados no Rio de Janeiro. Na ocasião, foi aprovada a "Carta do Rio" - conjunto de propostas que subsidiariam o Relatório do Brasil à Conferência de Durban. Conferiu-se destaque a propostas de ação afirmativa "que possibilitem a superação e o fim da reprodução de práticas e políticas socialmente discriminatórias” ${ }^{20}$, nas mais diversas áreas, incluindo a adoção de cotas em universidades, em cargos comissionados do serviço público, na publicidade oficial federal, nos concursos públicos, nas executivas partidárias e na mídia.

As propostas tiveram ressonância significativa no Relatório do Comitê Nacional para Durban, o qual apresentou revisão das medidas antidiscriminação adotadas no país, bem como diagnósticos e propostas de ação para o combate ao racismo. No conjunto de propostas, deve-se assinalar "a adoção de medidas reparatórias às vítimas do racismo, da discriminação racial e formas conexas de intolerância, por meio de políticas públicas específicas para a superação da desigualdade", as quais deveriam contemplar "medidas legislativas e administrativas destinadas a garantir a regulamentação dos direitos de igualdade racial previstos na Constituição de 1988, com especial ênfase nas áreas de educação, trabalho, titulação das terras". ${ }^{21}$

20 FUNDAÇÃ̄O CULTURAL PALMARES. A Fundação Cultural Palmares na III Conferência mundial de combate ao racismo, discriminação racial, xenofobia e intolerância correlata. Brasília: 2001.

21 Comitê nacional para a reparação da participação brasileira na III Conferência mundial das Naçôes Unidas contra o racismo, discriminação racial, xenofobia e intolerância correlata. Relatório. Brasília: Ministério da Justiça, 2001. p.19. 
Logo após Durban, o estabelecimento de canais de acesso ao processo decisório ganhou novo ímpeto com a criação, em outubro de 2001, do Conselho Nacional de Combate à Discriminação (CNCD), no âmbito do Ministério da Justiça. O CNCD, órgão colegiado composto de representantes governamentais e da sociedade civil - com ênfase especial na participação de entidades da comunidade negra -, foi criado com a competência de propor e avaliar políticas afirmativas de promoção da igualdade e de proteção dos direitos de indivíduos e grupos afetados por discriminação racial.

Tais desdobramentos refletiram-se em políticas. Uma avaliação dos principais instrumentos legais referentes ao tema (leis, decretos, portarias) adotados no Brasil desde 68 revela, em primeiro lugar, a intensificação de iniciativas a partir de 2001, quando passa a ser adotada a grande maioria dos instrumentos sob exame. Em segundo lugar, observa-se nítida diferenciação no tocante às características das iniciativas: as medidas implementadas antes de 2001 inserem-se nos padróes valorizativo ou repressivo, ao passo que as medidas adotadas a partir desta data inserem-se, predominantemente, no universo da ação afirmativa. Observam-se, ainda, referências à Conferência de Durban nos textos de todos os instrumentos legais que vieram a implementar políticas de ação afirmativa.

A partir de 2001, diversos órgãos do governo federal passaram a implementar iniciativas de combate à discriminação racial. O Ipea realizou estudos e pesquisas sobre a matéria, ao passo que os Ministérios da Justiça, do Desenvolvimento Agrário, da Educação, da Cultura e das Relações Exteriores implementaram programas e iniciativas de ação afirmativa. Em 2001, o Supremo Tribunal Federal passou a considerar constitucional o princípio da ação afirmativa, e adotou políticas de ação afirmativa a partir de 2002, passando a reservar $20 \%$ das vagas de subcontratados a afro-descendentes.

Em 2001, o Ministério do Desenvolvimento Agrário estabeleceu cotas para afro-descendentes em cargos de direção, no preenchimento de vagas em concurso público, e na contratação por empresas prestadoras de serviço e por organismos internacionais de cooperação técnica. Programas de Ação Afirmativa, prevendo o estabelecimento de cotas em moldes semelhantes, também foram adotados no Ministério da Justiça (Portaria 1.156, de 20.12.2001) e no Ministério da Cultura (Portaria 484, de 22.8.2002). O Ministério da Educação criou o Programa Diversidade na Universidade (Lei 10.558, de 13.11.2002), com a finalidade de promover o acesso de afro-descendentes e indígenas ao ensino superior; e o Ministério das Relações Exteriores - por meio do Protocolo de Cooperação sobre a Ação Afirmativa no Instituto Rio Branco, de 21.3.2002 - concedeu "bolsasprêmio de vocação para a diplomacia” em favor de estudantes afro-descendentes que viessem a candidatar-se ao Instituto Rio Branco.

Em maio de 2002, foi instituído o Programa Nacional de Ações Afirmativas, com o objetivo de coordenar as diversas iniciativas governamentais. Como objetivos específicos, o programa buscou promover: a) a observância, pelos órgãos 
da Administração Pública Federal, de metas percentuais de participação de afrodescendentes, mulheres e pessoas portadoras de deficiência no preenchimento de cargos em comissão de direção e assessoramento superiores; b) a concessão de pontuação adicional, nas licitações promovidas por órgãos da Administração Pública Federal, em benefício de fornecedores que adotassem políticas compatíveis com os objetivos do Programa; c) a inclusão, nas contratações de empresas prestadoras de serviços, de metas percentuais de participação de afro-descendentes, mulheres e pessoas portadoras de deficiência. No mesmo mês, o governo federal lançou a segunda edição do Programa Nacional de Direitos Humanos (PNDH II), também prevendo medidas de ação afirmativa: a) ampliação, no âmbito da União e dos estados e municípios, do acesso dos afro-descendentes às universidades públicas e aos cargos e empregos públicos; b) apoio às ações da iniciativa privada no campo da discriminação positiva.

No que tange ao combate à discriminação racial, podem-se identificar elementos de continuidade no período imediatamente posterior, quando tem início o Governo Luiz Inácio Lula da Silva. Tais elementos residiriam, sobretudo, na implementação de políticas públicas em conformidade com o modelo de ação afirmativa.

Em março de 2003, foi criada a Secretaria Especial de Políticas de Promoção da Igualdade Racial (Seppir), com status ministerial. Caberia à Seppir, entre outros atributos, coordenar políticas de diferentes ministérios e órgãos governamentais para a promoção da igualdade racial, e acompanhar o cumprimento de acordos e convenções internacionais. As diretrizes de atuação do Governo federal foram apresentadas mais detalhadamente com a divulgação, em novembro de 2003, da Política Nacional de Promoção da Igualdade Racial (Decreto n. 4.886). Entre diversos objetivos, o documento previa novas iniciativas públicas no plano da ação afirmativa, por meio de incentivos à adoção de políticas de cotas nas universidades e no mercado de trabalho, e à implementação de programas de diversidade racial em empresas.

De acordo com levantamento realizado, cerca de 26 iniciativas foram implementadas entre os anos de 2003 e 2004. ${ }^{22}$ Paralelamente - e em consonância com tendências observadas anteriormente -, foram instituídos novos canais de diálogo entre Governo Federal e sociedade civil, bem como entre Governo Federal e demais entes da federação, em matéria de combate à discriminação racial. Foi instituído o Conselho Nacional de Promoção da Igualdade Racial (Cnpir), com o objetivo de reforçar o diálogo entre Governo Federal e sociedade civil com vistas à implementação da Política Nacional de Promoção da Igualdade Racial. Também se deve registrar a constituição do Fórum Intergovernamental de Promoção da Igualdade Racial (Fipir), com o objetivo de fortalecer a cooperação entre os diferentes entes da Federação.

22 PAIXÃO, Marcelo. Conferência pela Promoção da Igualdade Racial - tese guia. Rio de Janeiro: 2004. 122p. p.106. 
Em julho de 2005 - declarado "Ano nacional da promoção da igualdade racial" -, foi realizada a $1^{\text {a }}$ Conferência nacional de promoção da igualdade racial ( $1^{\text {a }}$ Conapir). A conferência contou com a participação de aproximadamente mil delegados, e abordou a promoção da igualdade nas três instâncias de governo e o cumprimento dos compromissos internacionais, entre outros eixos temáticos.

Com base nas considerações apresentadas, pode-se constatar marcada intensificação de iniciativas governamentais de combate ao racismo - e na implementação de ações afirmativas, em particular - no período que teve início com a preparação da participação brasileira na Conferência de Durban. Embora o período 1995-2005 se distinga, em geral, no tocante aos padróes e à intensidade da ação governamental em matéria de combate ao racismo, o sub-período com início em 2000 representaria novo patamar no tocante à proliferação de iniciativas e à instituição de canais de diálogo com setores organizados da sociedade civil. A consideração de que a Conferência de Durban teria representado "momentochave" internacional para catalisar e intensificar iniciativas de combate ao racismo no Brasil - particularmente no plano da ação afirmativa - tem ressonância em reflexôes provenientes de fontes governamentais e da sociedade civil:

A convocação da $3^{a} \mathrm{CMR}$ significou uma oportunidade inédita de mobilização do Estado brasileiro e da sociedade civil em torno dos temas relacionados ao racismo, permitindo não só uma observação de sua incidência no país, mas também um olhar sobre a diáspora africana, em especial na América Latina e no Caribe. (...) Diferentes setores avaliam que, de fato, o processo e os acordos da $3^{\text {a }} \mathrm{CMR}$ vieram a significar, antes de tudo, a ampliação dos espaços de disputa contra o racismo, bem como a mobilização de novos atores e a inserção em novas estruturas estatais. ${ }^{23}$

\section{Conclusões}

No tocante às políticas públicas de combate à discriminação racial no Brasil, teria ocorrido uma transição entre cenário de "integração incipiente" - que caracterizaria o relacionamento entre Brasil e ambiente internacional durante as décadas de 60 e 70, principalmente - para situação de "integração plena" que caracterizaria o padrão daquele relacionamento a partir dos anos 90 . Os fundamentos da transição devem ser buscados no comportamento do sistema internacional - desenvolvimento do ambiente normativo e institucional relativo ao combate à discriminação racial - e na evolução da realidade política e institucional do Brasil - configuração de canais de acesso ao processo decisório governamental, e organização dos grupos com interesse mais direto na matéria.

Com relação ao ambiente internacional, pode-se concluir que o sistema normativo de combate à discriminação racial se tornou mais denso a partir dos anos

23 WERNECK, Jurema. A Luta Continua: o combate ao racismo no Brasil pós-Durban. Observatório da Cidadania. Brasília: 2005. 
60, e passou a dispor de instrumentos de pressão mais claramente identificados. Por outro lado, o sistema político e institucional brasileiro foi marcado por dois processos paralelos: a) a redemocratização do país, com a instituição de canais de acesso da sociedade civil ao processo decisório relativo às políticas públicas; b) a crescente organização do movimento negro brasileiro. A tais fatores deve ser agregada a compatibilidade entre a pressão dos grupos interessados em políticas mais efetivas de combate ao racismo e a distribuição de preferências do Poder Executivo, no tocante à matéria, no período 1995-2005.

O período de "transição" foi possivelmente caracterizado por maior pressão internacional por adesão ao sistema normativo, elevação dos custos de "audiência" e de "reputação" de descumprimento das normas internacionais de combate ao racismo, e maior sensibilidade das preferências estatais à "pressão" internacional. Embora se registrem, no período, episódios de pressão "tradicional" da comunidade internacional, provavelmente tiveram mais eficácia as "pressões" conduzidas ao amparo de canais de "persuasão" - associados aos efeitos constitutivos da abertura ao sistema internacional - e de "mobilização" - associados ao impulso político conferido por eventos internacionais a iniciativas domésticas.

O canal de persuasão esteve em construção progressiva no período, à luz da participação do país nas principais iniciativas, e do diálogo do Brasil com as principais instituições internacionais com atribuições na matéria. Por sua vez, o canal da "mobilização" está fundamentalmente associado à realização da Conferência de Durban, em 2001. O processo preparatório da participação brasileira, e a própria abrangência das deliberações em Durban, conferiram impulso significativo à implementação de políticas públicas mais incisivas no tocante à redução de desigualdades raciais.

Ao instituírem canais mais amplos e diretos de acesso de grupos organizados ao processo decisório, e ao elevarem o perfil político do tema, os processos de preparação e de implementação das recomendações de Durban geraram condições favoráveis à atuação governamental com o objetivo de reduzir desigualdades raciais. Tais condiçōes favoreceram a implementação de programas de ação afirmativa no país, os quais já integravam, há tempos, o rol de demandas do movimento negro organizado.

Sob esta perspectiva, a interrelação entre ambiente internacional - sobretudo a mobilização associada ao "momento-chave" consagrado por Durban - e realidade política doméstica possibilitaram a implementação de políticas com impactos redistributivos. Viabilizaram, neste contexto, a superação de "pontos de veto", usualmente associados a focos de resistência difusa, na opinião pública brasileira, à rationale que tem norteado a implementação de programas de ação afirmativa.

Recebido em 9 de fevereiro de 2008 Aprovado em 16 de setembro de 2008 


\section{Resumo}

Neste artigo, examina-se como a exposição do Estado a normas internacionais pode condicionar a implementação de políticas redistributivas, a partir de estudo de caso relativo ao combate à discriminação racial no Brasil, no período 1995-2005. Conclui que o processo de preparação e de seguimento da Conferência de Durban teria viabilizado equilíbrio propício à implementação de políticas de ação afirmativa.

\section{Abstract}

This paper analyzes how the State acceptance of international norms may influence the implementation of redistributive policies, based on a case study of policies against racial discrimination in Brazil, from 1995 to 2005. It argues that the preparation of and the follow-up to the Durban Conference would have increased the political feasibility of affirmative action policies in Brazil.

Palavras-chave: Redistribuição; Normas; Discriminação racial; Ação afirmativa Key words: Redistribution; Norms; Racial discrimination; Affirmative action 